echocardiography, a more reliable and reproducible method for quantifying MR. ${ }^{8}$ This is an important limitation because it is the precise degree of MR that is being placed into the equation of analysis for the patient's long-term survival. In this era, echocardiography should be the standard for the diagnosis and evaluation of functional MR.

Additionally, the authors' conclusion that there was "progression of the MR" in their patients is difficult to substantiate because less than one third of the patients had any echocardiographic follow-up. In fact, this circumstance might have led to skewing of the follow-up dataset because those patients with more congestive heart failure might have been more likely to have been followed with echocardiography. Problematically, there is also a lack of granularity in Dr Mallidi's analysis of preoperative ventricular function and clinical status. Because more than half of the patients had ejection fractions of greater than $40 \%$, it is confusing why almost $89 \%$ of the patients without any MR were preoperatively categorized in New York Heart Association class 3 or 4 . From this dataset, it still remains unanswered whether those patients with reduced ventricular function had poorer outcomes. This is an especially important question because it is those patients who are the most important in this discussion. As Dr Gorman pointed out in his commentary on the Tolis article, ischemic MR can be thought of as the "ventricle crying out for help." 9

The article by Mallidi and colleagues ${ }^{1}$ adds to our knowledge as we attempt to deal with this difficult clinical choice. Our research efforts should remain focused on those patients with impaired ventricular function, the "sows' ears" who are at greatest risk for diminished late survival. It is in this patient subset that we might have the capability to improve outcomes. The question still remains open: In which patients and with what degree of ischemic MR will intervention provide improved survival, thereby justifying an added risk to the operative procedure?

\section{References}

1. Mallidi HR, Pelletier MP, Lamb J, Desai N, Sever J, Christakis GT, et al. Late outcomes in patients with uncorrected mild to moderate mitral regurgitation at the time of isolated coronary artery bypass grafting. J Thorac Cardiovasc Surg. 2004;127:636-44.

2. Miller DC. Ischemic mitral regurgitation redux - to repair or to replace? J Thorac Cardiovasc Surg. 2001;122:1059-62.

3. Grigioni F, Enriquez-Sarano M, Zehr KJ, Bailey KR, Tajik AJ. Ischemic mitral regurgitation: long-term outcome and prognostic implications with quantitative Doppler assessment. Circulation. 2001;103:1759-64.

4. Ellis SG, Whitlow PL, Raymond RE, Schneider JP. Impact of mitral regurgitation on long-term survival after percutaneous coronary intervention. Am J Cardiol. 2002;89:315-8.

5. Harris KM, Sundt TM 3rd, Aeppli D, Sharma R, Barzilai B. Can late survival of patients with moderate ischemic mitral regurgitation be impacted by intervention on the valve? Ann Thorac Surg. 2002;74: 1468-75.

6. Tolis GA Jr, Korkolis DP, Kopf GS, Elefteriades JA. Revascularization alone (without mitral valve repair) suffices in patients with advanced ischemic cardiomyopathy and mild-to-moderate mitral regurgitation. Ann Thorac Surg. 2002;74:1476-81.

7. Duarte IG, Shen Y, MacDonald MJ, Jones EL, Craver JM, Guyton RA. Treatment of moderate mitral regurgitation and coronary disease by coronary bypass alone: late results. Ann Thorac Surg. 1999;68:426-30.

8. Castello R, Lenzen P, Aguirre F, Labovitz AJ. Quantitation of mitral regurgitation by transesophageal echocardiography with Doppler color flow mapping: correlation with cardiac catheterization. J Am Coll Cardiol. 1992;19:1516-21.

9. Gorman RC, Gorman JH. Does repair of ischemic mitral regurgitation help? Ann Thorac Surg. 2003;76:1775-6.

\title{
The Journal of Thoracic and Cardiovascular Surgery Conflict of Interest Policy
}

To assure fairness to authors submitting work for consideration in The Journal of Thoracic and Cardiovascular Surgery, a mechanism exists for managing conflicts of interest. The editor and each of the section editors complete a "Conflict of Interest" form that identifies any and all relationships with commercial and other academic entities. When the editor has a potential conflict because of a relationship with another entity or author, the editor appoints an alternate editor from among the section editors or editorial board members who assumes the entire responsibility for final decisions on the manuscript in question. The editor does not read the reviews that are submitted nor engage in discussing the manuscript prior to the final decision. When the conflict of interest involves a section editor, a "guest section editor" is appointed who fills the role normally played by the conflicted section editor. All members of the editorial board and reviewers are asked to indicate any conflict of interest when they agree to review a manuscript. 